\title{
Assessment of long term patient satisfaction in orthognathic surgery
}

\author{
Ibrahim Tabakan ${ }^{1}$, Omer Kokacya $^{2 *}$, Erol Kesiktas ${ }^{3}$, Cengiz Eser ${ }^{3}$, Eyuphan Gencel ${ }^{3}$
}

\begin{abstract}
Objective: Even though there are many reliable sets of data on orthognathic surgery, there is very little information about patients' satisfaction. When evaluating the success of the surgeries, clinicians usually take postoperative occlusion and cephalometric measurements into consideration. However for the patients, aesthetic appearence is just as important as occlusion.
\end{abstract}

Material and Method: Eighty patients who underwent orthognathic surgery between 2003-2011 in Cukurova University were studied. Patients were interviewed either personally or by phone using a questionnaire reflecting patient satisfaction such as preoperative and postoperative aesthetic facial apperance, change in self confidence, mastication, hypoesthesia and pain in the temporomandibular joint.

Results: $22.5 \%$ of the patients stated that there was aesthetic improvement, $8.8 \%$ stated only improvement in mastication and $62.5 \%$ stated there was improvement in both. A total of $70 \%(n=56)$ of the patients pointed out there was significant improvement in their self esteem.

Conclusion: This study suggests that the outcome of surgeries can be evaluated not only by occlusion and cephalometric measurements, but also with subjective complaints and satisfaction of the patients. To achieve long term success in orthognathic surgery, one should know the relationship between function and aesthetic facial appearence and take both of them into consideration equally.

Keywords: Malocclusion, LeFort1 osteotomy, sagittal split ramus osteotomy, patient satisfaction

\section{Introduction}

Orthognathic surgery involves surgical manipulation of facial skeleton elements to restore the proper anatomic and functional relationship in patients with dentofacial skeletal anomalies. Skeletal and dental anomalies of the jaws have a broad spectrum including congenital, developmental, and acquired deformities $(1,2)$. Dentofacial anomalies may cause temporomandibular joint (TMJ) dysfunction, imperfect mastication due to irregular teeth, poor oral hygiene and psychological problems accompanied by inappropriate face appereances $(3,4)$. A vast majority of these problems can be solved succesfully with orthodontic treatment that is started at early childhood stages. After the skeletal maturation is completed, following orthodontic treatment surgical procedures may be needed to restore neutral occlusion and appropriate anatomic architecture. The most employed orthognathic surgeries are LeFort1 osteotomy for maxilla and bilateral saggital split ramus osteotomy (BSSRO) for mandible (5-8). Patient's satisfaction after orthognathic surgery is usually high. Because the major complications rate is low and minor complications can be managed succesfully with conservative approaches $(9,10)$.

In this study, long term results and satisfaction status of orthognathic surgery patients have been evaluated.

\section{Material and Methods}

In this study, 80 patients underwent LeFort1 osteotomy, BSSRO or both (two-jaw) due to developmental malocclusion between 2003-2011 in Cukurova University Faculty of Medicine, Department of Plastic, Reconstrutive and Aesthetic Surgery with at least 1 year postoperative follow up period were included. Patients with cleft lip and/or palate, congenital syndromes, malocclusion secondary to trauma and the ones in whose surgery 
osteodistraction was performed were excluded. Medical records of 147 patients meeting the criteria of the study were scanned retrospectively and 80 patients we could reach were included.

Patients were divided into 3 groups: Group 1, two-jaw surgery $(n=35)$; group 2, LeFort1 osteotomy $(n=24)$; group 3, BSSRO $(\mathrm{n}=21)$.

Patients were interviewed either personally or by phone with using a 13 question questionnaire. Table 1 reflects patients' satisfaction such as preoperative and postoperative aesthetic facial apperance, change in self confidence, mastication, hypoesthesia and pain in TMJ.
Statistical analysis was done using SPSS, version 17.0 (SPSS, S.L. Madrid, Spain). Categorical variables were summerized as numbers or percentages while continuous variables were summerized as means and standard deviations (median and minimummaximum where necessary). Ki-kare and Fisher tests were used for the comparison of categorical variables. For the comparison of continuous variables, T test and ANOVA were used at normally distributed parameters and Mann Whitney $U$ and Kruscal Wallis test was used at non-normally distributed parameters. Wilcoxson, Friedman and Repeated Measures Analyses were used for preoperative and postoperative assessments. Statistical significance level was taken $\mathrm{p}<0.05 \%$ for each test.

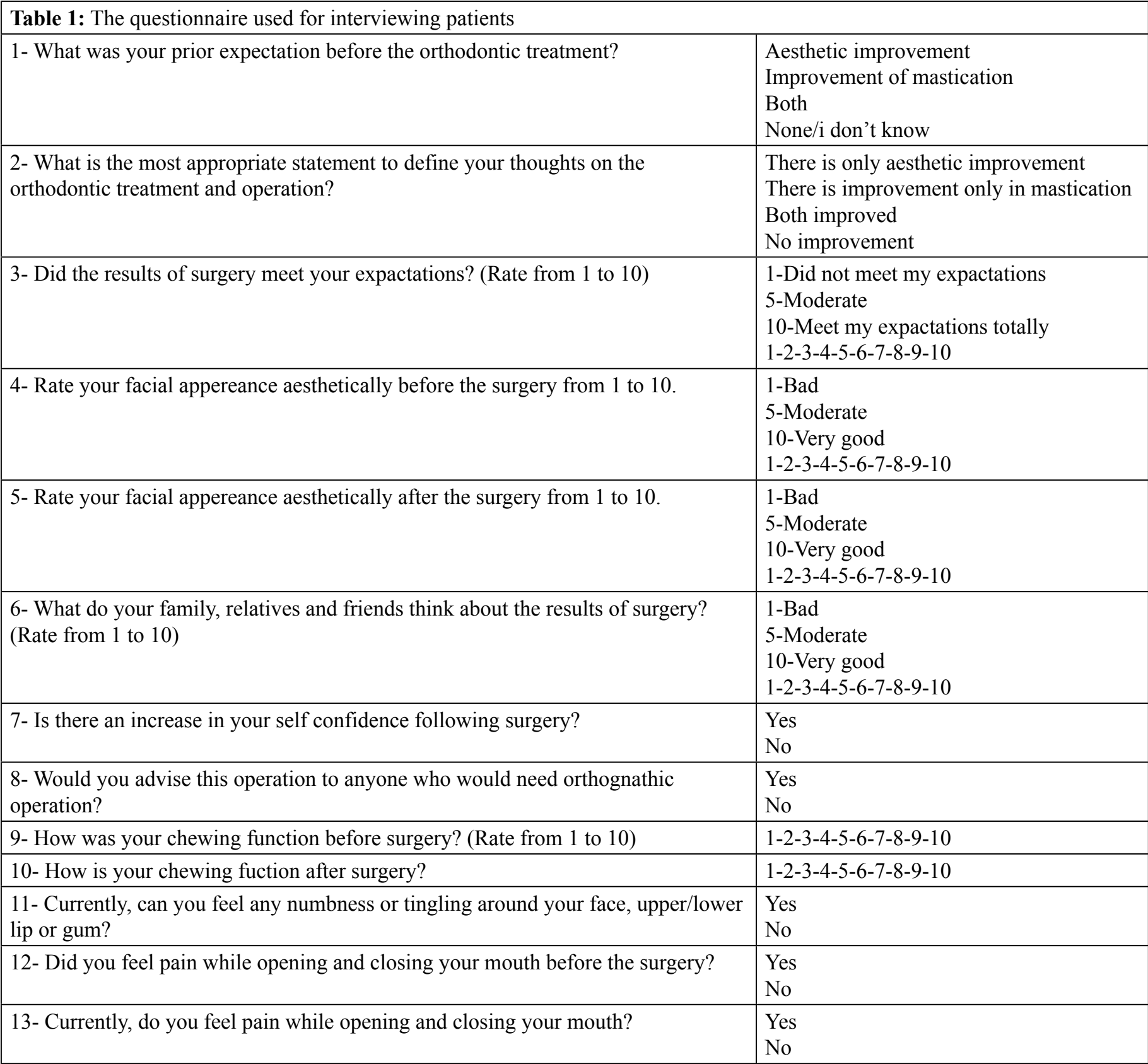




\section{Results}

Age and sex distribution of the patients are shown in Table 2.

Results of the answers for question 1 and 2, which reflect the expectations and if the expectations are met, they are summerized in Table 3.

The $3^{\text {rd }}$ question is scrutinizing if the result of the surgery met the expactations yielded the result of $8.4 \pm 1.3$ (mean \pm SD). $17.5 \%(n=14)$ of patients answered this question with full score, 10 points.

Results of the $4^{\text {th }}$ and $5^{\text {th }}$ question asking the patients to rate their facial appereance aesthetically from 1 to 10 before and after the surgery are shown in Table 4. Difference between before and after surgery was statistically significant in all groups and in total population $(\mathrm{p}=0.0001)$. However, there was no statistical significant difference between the groups $\left(p^{*}=0.056\right)$.

The $6^{\text {th }}$ question that scrutinizes thoughts of patient's family, relatives and friends about the result of the surgery yielded the result of $8.5 \pm 1.2$ (mean $\pm \mathrm{SD}$ ) for group 1, 8.7 \pm 1.2 (mean \pm $\mathrm{SD}$ ) for group 2, $8.9 \pm 1.0$ (mean $\pm \mathrm{SD}$ ) for group 3 and $8.6 \pm 1.1$ (mean \pm SD) for the total population. When we compared the results from question 5 and 6 , we did not see any statistical significant difference between the patients self evaluation and opinion of the patient's family, relatives and friends about the result of the surgery.

Results of the $7^{\text {th }}$ question showed that there was an increase in self confidence at $65.7 \%(\mathrm{n}=23)$ of patients in group $1,70.8 \%$ $(n=17)$ of patients in group $2,76.2 \%(n=16)$ of patients in group 3 and $80 \%(n=56)$ of total population.

Outcomes from the $8^{\text {th }}$ question showed that in group $168.6 \%$ $(\mathrm{n}=24)$, in group $2,83.3 \%(\mathrm{n}=20)$, in group 3, 81.0\% $(\mathrm{n}=17)$ and in total population $76.3 \%(n=61)$ of the patients would advise this operation to individuals who would need orthognathic operation.

Results from the $9^{\text {th }}$ and $10^{\text {th }}$ question evaluating preoperative and postoperative chewing functions are shown in Table 5.
The $11^{\text {th }}$ question gave the results of $37.1 \%(n=13)$ of patients in group $1,25.0 \%(\mathrm{n}=6)$ of patients in group $2,38.1 \%(\mathrm{n}=8)$ of patients in group 3 and $33.8 \%(n=27)$ the total number of patients have reported numbness or tingling around their faces, upper/lower lip or gum.

Outcomes from question 12 and 13 that scrutinize pain in TMJ while opening and closing their mouth before and after surgery show that in group 1 before surgery $25.7 \%(n=9)$ and after surgery $31.5 \%(n=11)$ feel pain. In group 2 , it was $8.3 \%(n=2)$ before and again $8.3 \%(n=2)$ after surgery. In group 3 , it was $14.3 \%(n=3)$ before and $38.1 \%(n=8)$ after surgery. In the total number of patients, while $17.5 \%(n=14)$ of patients used to feel pain in TMJ before surgery, $26.3 \%(n=21)$ of patients felt pain after surgery.

\section{Discussion}

Dentofacial deformities drastically affect patient's healthrelated qualities of life. Especially unaesthetic appereances of soft tissue and skeletal architecture in class 3 deformities may cause psychological problems (11). Therefore, the most crucial step of preoperative planning in orthognathic surgery candidates is psychological assessment. Ideally, a psychiatrist or psychologist should undertake this assesment. If this can not be provided, an orthodontist or surgeon should evaluate the patient carefully. Patient's self perception of facial appeareance can differ from physicians perception. Therefore, patient's subjective complaints and expectations should be analized carefully. Physicians should decide whether they can meet these expectations (12).

Studies show that even if there are minor disparities in the results, patients are satisfied with the results of orthognathic surgeries. There are many factors that might cause postoperative dissatisfaction. Most of them are secondary to miscommunication of patient and physician rather than poor postoperative results or lack of surgical skills.

Many measurement indexes are used for assessing the benefits of orthognathic surgery and usually questionnaires are preferred.

\begin{tabular}{|c|c|c|c|c|c|c|c|c|c|}
\hline & \multicolumn{2}{|c|}{$\begin{array}{l}\text { Two-jaw surgery } \\
\text { group } 1(\mathrm{n}=35)\end{array}$} & \multicolumn{2}{|c|}{$\begin{array}{l}\text { LeFort1 osteotomy } \\
\text { group } 2(n=24)\end{array}$} & \multicolumn{2}{|c|}{$\begin{array}{l}\text { BSSRO } \\
\text { group } 3(n=21) \\
\end{array}$} & \multicolumn{2}{|l|}{$\begin{array}{l}\text { Total } \\
(\mathbf{n}=\mathbf{8 0})\end{array}$} & \multirow[b]{2}{*}{ p } \\
\hline & Mean \pm SD & $\begin{array}{l}\text { Med } \\
(\text { min-max) }\end{array}$ & Mean \pm SD & $\begin{array}{l}\text { Med } \\
(\min -\max )\end{array}$ & Mean \pm SD & $\begin{array}{l}\text { Med } \\
(\text { min-max) }\end{array}$ & Mean \pm SD & $\begin{array}{l}\text { Med } \\
\text { (min-max) }\end{array}$ & \\
\hline Age & $21.9 \pm 2.8$ & $22(18-30)$ & $22.7 \pm 3.8$ & $22(17-32)$ & $22.7 \pm 4.0$ & $22(17-35)$ & $22.4 \pm 3.4$ & $22(17-35)$ & 0.606 \\
\hline Sex & $\mathrm{n}$ & $\%$ & $\mathrm{n}$ & $\%$ & $\mathrm{n}$ & $\%$ & $\mathrm{n}$ & $\%$ & $\mathrm{p}$ \\
\hline Female & 28 & 80 & 16 & 66.7 & 12 & 57.1 & 56 & 70 & \multirow{2}{*}{0.178} \\
\hline Male & 7 & 20 & 8 & 33.3 & 9 & 42.9 & 24 & 30 & \\
\hline
\end{tabular}

p: Kruskal Wallis Test used for age distrubition, SD: Standard deviation, BSSRO: Bilateral saggital split ramus osteotomy, min: Minimum, max: Maximum 
Orthodontic indexes assess the success of the operation by classifying patients occlusion with numerical values. These indexes are commonly used in Europe.

In 1998, O'Brien et al. (13) studied life quality of orthodonthy patients and they reported that most measurements developed for dentistry should not be used for orthodontic patients, because most of the orthodontic anomalies are asymptomatic and most of the orthodontic anomalies are related with aesthetic apperreance rather than symptoms like pain.
In 1999, Bennett and Phillips reported that there are significant differences between physicians' results and patients' subjective assesment (14).

These studies directed the physicians to make patient-centered treatment plans and Ortognathic Quality of Life Questionnaire to be formed. This questionnaire is easily and quickly applicable and economic, however, it should be kept in mind that it is subjective because replies can be effected by patients' moods at the time of quastionnaire.

Table 3: Results of the answers for question 1 and 2

\begin{tabular}{|c|c|c|c|c|c|c|c|c|c|}
\hline \multirow[b]{2}{*}{$\begin{array}{l}\text { Question } 1 \\
\text {-What was your prior expectation before the orthodontic treatment? }\end{array}$} & \multicolumn{2}{|c|}{\begin{tabular}{|l|}
$\begin{array}{l}\text { Group } 1 \\
(\mathbf{n}=\mathbf{3 5})\end{array}$ \\
\end{tabular}} & \multicolumn{2}{|c|}{\begin{tabular}{|l|}
$\begin{array}{l}\text { Group } 2 \\
(\mathrm{n}=\mathbf{2 4})\end{array}$ \\
\end{tabular}} & \multicolumn{2}{|c|}{$\begin{array}{l}\text { Group } 3 \\
(\mathbf{n}=21)\end{array}$} & \multicolumn{2}{|c|}{$\begin{array}{l}\text { Total } \\
(\mathbf{n}=\mathbf{8 0})\end{array}$} & \multirow[b]{2}{*}{$\mathbf{p}$} \\
\hline & $\mathbf{n}$ & $\%$ & $\mathbf{n}$ & $\%$ & $\mathbf{n}$ & $\%$ & $\mathbf{n}$ & $\%$ & \\
\hline Aesthetic improvement & 14 & 40 & 6 & 25.0 & 4 & 19 & 24 & 30 & \multirow{4}{*}{0.439} \\
\hline Improvement of mastication & 4 & 11.4 & 5 & 20.8 & 6 & 28.6 & 15 & 18.8 & \\
\hline Both & 16 & 45.7 & 13 & 54.2 & 11 & 52.4 & 40 & 50 & \\
\hline None/i don't know & 1 & 2.9 & 0 & 0.0 & 0 & 0.0 & 1 & 1.3 & \\
\hline $\begin{array}{l}\text { Question } 2 \\
\text {-What is the most appropriate statement to define your thoughts on the } \\
\text { orthodontic treatment and operation? }\end{array}$ & $\mathbf{n}$ & $\%$ & $\mathbf{n}$ & $\%$ & $\mathbf{n}$ & $\%$ & $\mathbf{n}$ & $\%$ & $\mathbf{p}$ \\
\hline There is only aesthetic improvement & 9 & 25.7 & 4 & 16.7 & 5 & 23.8 & 18 & 22.5 & \multirow{4}{*}{0.988} \\
\hline There is improvement only in mastication & 3 & 8.6 & 2 & 8.3 & 2 & 9.5 & 7 & 8.8 & \\
\hline Both improved & 21 & 60.0 & 16 & 66.7 & 13 & 61.9 & 50 & 62.5 & \\
\hline No improvement & 2 & 5.7 & 2 & 8.3 & 1 & 4.8 & 5 & 6.3 & \\
\hline
\end{tabular}

Table 4: Self evaluation of facial appereance before and after surgery

\begin{tabular}{|c|c|c|c|c|c|c|}
\hline & \multicolumn{2}{|c|}{ Before surgery } & \multicolumn{2}{|c|}{ After surgery } & \multirow[b]{2}{*}{$\mathbf{p}$} & \multirow[b]{2}{*}{$\mathbf{p}^{*}$} \\
\hline & Mean \pm SD & Med (min-max) & Mean \pm SD & Med (min-max ) & & \\
\hline Total & $5.1 \pm 1.0$ & $5(3-7)$ & $8.4 \pm 1.3$ & $9(5-10)$ & 0.0001 & \\
\hline Group 1 & $5.4 \pm 0.9$ & $5(3-7)$ & $8.2 \pm 1.3$ & $9(5-10)$ & 0.0001 & \multirow{3}{*}{0.056} \\
\hline Group 2 & $5.1 \pm 1.0$ & $5(3-7)$ & $8.4 \pm 1.4$ & $9(5-10)$ & 0.0001 & \\
\hline Group 3 & $4.6 \pm 1.1$ & $5(3-7)$ & $8.7 \pm 1.2$ & $9(6-10)$ & 0.0001 & \\
\hline
\end{tabular}

p: Friedman test and Wilcoxson test, p*: Repeated measure analysis-Greenhouse Geisser test, SD: Standard deviation, min: Minimum, max: Maximum

\begin{tabular}{|c|c|c|c|c|c|c|}
\hline & \multicolumn{2}{|c|}{ Before surgery } & \multicolumn{2}{|c|}{ After surgery } & \multirow[b]{2}{*}{$\mathbf{p}$} & \multirow[b]{2}{*}{$p^{*}$} \\
\hline & Mean \pm SD & Med (min-max) & Mean \pm SD & Med (min-max) & & \\
\hline Group 1 & $5.7 \pm 1.0$ & $6(3-8)$ & $7.6 \pm 1.3$ & $7(4-10)$ & 0.0001 & \multirow{3}{*}{0.001} \\
\hline Group 2 & $4.4 \pm 1.1$ & $4(3-7)$ & $8.2 \pm 1.6$ & $9(5-10)$ & 0.0001 & \\
\hline Group 3 & $4.2 \pm 1.2$ & $4(2-6)$ & $8.0 \pm 1.5$ & $8(5-10)$ & 0.0001 & \\
\hline Total & $4.9 \pm 1.3$ & $5(2-8)$ & $7.9 \pm 1.5$ & $8(4-10)$ & 0.0001 & \\
\hline
\end{tabular}

p: Friedman test and Wilcoxson test, $\mathrm{p}^{*}$ : Repeated measure analysis-Greenhouse Geisser test, SD: Standard deviation 
Young male patients expect functional improvements primarily, while young female patients prior expectations are aesthetical improvements and therefore increase in self confidence (15). Nicodema et al. (16) reported remission in depression symptoms together with increase in self confidence following surgery at elderly female class 3 malocclusion patients while there was no change in male patients.

Rustmeyer et al.'s (17) study included patients with class 3 occlusion at the age of 23 in average and they reported that there was no significant difference between genders from a satisfaction point of view. The same study showed significant improvements in patients who had TMJ problems (pain, limitations in mouth opening) before surgery. A few patients that came along with TMJ problems after surgery were followed with splint and physiotherapy.

In our study, there is no significant difference between genders in the "satisfaction" context like Rustmeyer et al.'s (17) study, but our TMJ results are different. Before surgery, $17.5 \%(\mathrm{n}=14)$ patients had TMJ pain and after surgery it was $26.3 \%(n=21)$ patients. While 14 patients suffering from pain did not recover; 7 patients started to feel pain after surgery. In our opinion, this is an exaggerated result because some patients stated that pain relieved spontaneously when they went back to their social life.

One of the most frequent consequences following BSSRO are sensation changes at mentum, lips, and gum as a result of inferior alveolar nerve (IAN) injury. It is believed $85-100 \%$ of the patients at the early postoperative period and by decreasing over time, full recovery expected (18-20). Raveh et al. (21) reported $97 \%$ neurosensational loss after BSSRO at the early postoperative period. Studies with more than 500 patients showed that permanent nerve injury at long term period is between $32-39 \%(8,22)$. High rates of IAN injury even after 1 year postoperative period is one of the disadvantages of BSSRO $(23,24)$.

Westermark et al.'s (25) study, which is the biggest series with 496 BSSRO patients, reported $66 \%$ hypoesthesia due to varying degrees of nerve injury. They indicated that nerve injury is more frequent in elderly patients and they emphasized the importance of the surgical experience.

In our study, the IAN injury rate after BSSRO is $38.1 \%(\mathrm{n}=8)$ and after two-jaw surgery $37.1 \%(\mathrm{n}=13)$. In order to obtain clearer results about the IAN injury, peroperative and postoperative two point discrimination, light touch, needle pricking and coldhot discrimination tests as performed in the study of Ylikontiola et al. (26) should have been employed.

Overall, our patients found the surgeries successful. Only $6.3 \%$ of our patients think that there is neither aesthetical nor functional improvement. Opinions patient's familiy, relatives and friends are similar. There were significant differences between preoperative and postoperative self assessment of facial aesthetic aperreance in all groups $(\mathrm{p}=0.0001)$. Percent of $70(n=56)$ patients found increase in their self confidence and $76.3 \%(\mathrm{n}=61)$ would advise the operation to other candidates. The rate of positive advise was lower in group 1 (two-jaw) compared to the rest of the groups. This might be due to more powerful postoperative pain and swelling as the operation is more complicated.

Van de Perre et al.'s (27) retrospective study with 2.049 patients communicates that the most common complication of maxillary orthognathic surgery is severe bleeding, but in Kramer et al.'s (28) study with 1000 LeFort 1 osteotomies only $1.1 \%(n=11)$ patients had blood transfusion and in only in 1 patient external carotid artery ligation was performed.

Panula et al. (8) reported $1 \%$ transfusion rate in BSSRO patients and $17 \%$ in LeFort 1 osteotomy patients. Transfusion need is lower in mandibular osteotomies than maxillary osteotomies. Retromandibular vein, internal maxillary artery, facial artery and inferior alveolar artery are the most commonly injured vessels (8). Cautious subperiosteal dissection and ecartation of vessels decreases bleeding.

Compression during the operation can stop the bleeding. Topical hemostatic agents and fibrin including hemostatic filling materials can be used. In case of persistant or recurrent bleeding ligation or embolisation ef external carotid artery can be necessary (8).

One of the worst complications of LeFortl osteotomy is aseptic necrosis. This complication is very rare because of extensive vascularization of maxilla. However, tension of the palatal vascular pedicle, seperation of maxillary segments, injury of descendant palatine artery, injury of palatal mucosa, overdissection of maxilla and accompanying hypotension may result in aseptic ischemic necrosis (29). After the LeFort1 osteotomy was completed, maxillary vascularization is ensured by branches of descendant palatine artery, branches of posterior superior alveolar artery to soft tissue, palatal branch of ascendent pharangeal artery and palatal branch of facial artery (29-30).

Skeletal relapse is the most common complication of orthognathic surgery (31). Bone fixation is mandatory for preventing skeletal relapse. Stability is closely related with the direction and amount of movement, type of fixation, surgical technique and vascularity of bone segments $(31,32)$. When we consider the direction of movement from the aspect of stabilization, the most stable technique is upper movement of maxilla and advancement of mandible. The least stable technique is the down movement of maxilla and maxillary expansion (32). 
According to the description of rigid fixation techniques, it has an increased stability, but rigid fixation can not guarentee stability in every patient. Hoffman and Brennan (33) reported $10 \%$ relapse in maxillary advancement patients in whose operation rigid fixation was used.

Relapse is related with upper movement of mandible by mastication muscles and thereby pushing of maxilla upwards by mandible. Research studies report up to $48 \%$ relapse rates (34). When maxillary bone grafting is used with rigid fixation, relapse rates can decrease to $4 \%$ (35).

In our study, we did not see any major complications. Minor complications experiences have been summerized below.

A patient who had two-jaw surgery operation were reoperated at the postoperative $25^{\text {th }}$ day because of nonunion and bone gap in the mandiblular osteotomy line was repaired with bone graft.

Another two-jaw patient was reoperated due to unnoticed hematome. The operation was completed with compression after applying the hemostatic material. Same patient was operated 2 months later due to lateralization. There was malunion at mandibular osteotomy line and a new fixation was made.

A patient who underwent BSSRO was reaoperated after 6 hours because of malocclusion and rigid fixation was renewed.

A patient whose mandibular bone segment was exposed through mucosa was reoperated in order to excise exposed bone segment.

One LeFort1 and 2 two-jaw patients were reoperated in late postoperative period in order to remove exposed titanium plates.

One LeFort1 osteotomy patient underwent seprorhinoplasty operation at the late postoperative period because of nasal septum deviation.

\section{Conclusion}

This study suggests that outcomes of the surgeries can be evaluated not only by occlusion and cephalometric measurements, but also with subjective complaints and satisfaction of the patients. To achieve long term success in orthognatic surgery, one should know the relationship between function and aesthetic facial appearence and take both of them into consideration equally.

Acknowledgments: We would like to thank to Cukurova University, Faculty of Dentistry and Department of Orthodonthy on the ground for sharing medical records with us.

Conflict of Interest: We have no conflict of interest to declare.

\section{References}

1. Patel PK, Morris DE, Zhao L. Orthognathic Surgery. (Updated: 12.02.2014, Access time: 25.02.2016) Available from: http://emedicine. medscape.com/article/1279747-overview

2. Rosen HM. Aesthetic Orthognathic Surgery. In: Mathes SJ, Hentz VR, editors. Plastic Surgery. Philadelphia: Saunders Elsevier; 2006. p. 649686

3. Berger JL, Pangrazio-Kulbersh V, Bacchus SN, Kaczynski R. Stability of bilateral sagittal split ramus osteotomy: Rigid fixation versus transosseous wiring. Am J Orthod Dentofacial Orthop. 2000;118:397403.

4. Hoppenreijs TJ, Freihofer HP, Stoelinga PJ, Tuinzing DB, van't Hof MA. Condylar remodelling and resorption after Le Fort I and bimaxillary osteotomies in patients with anterior open bite: A clinical and radiological study. Int J Oral Maxillofac Surg. 1998;27:81-91

5. Tucker MY, Ochs MW. Correction of dentofacial deformities. In Peterson LJ, Edward E, Hupp JR, Tucker MR, editors. Contemporary Oral and Maxillofacial surgery. 4th ed. New York: Mosby; 2003. p. 559-602.

6. Schendel SA. Orthognathic surgey. In: Achauer BM, Eriksson E, Guyuron B, Coleman JJ, Russell RC, Vander Kolk CA, editors. Plastic Surgery. St. Louis: Mosby; 2000. p. 871-895.

7. Bailey LT, Proffit WR, White RP Jr. Trends in surgical treatment of class III skeletal relationships. Int J Adult Orthodon Orthognath Surg. 1994;10:108-118.

8. Panula K, Finne K, Oikarinen K. Incidence of complications and problems related to orthognathic surgery: A review of 655 patients. J Oral and Maxillofac Surg. 2001;59:1128-1136.

9. Schendel SA, Mason ME. Adverse outcomes in orthognathic surgery and management of residual problems. Clin Plast Surg. 1997;24:489505 .

10. Borstlap W, Stoelinga PJ, Hoppenreijs TJ, Van’t Hof MA. Stabilisation of sagittal split advancement osteotomies with miniplates: A prospective, multicentre study with two-year follow-up: Part I. Clinical parameters. Int J Oral Maxillofac Surg. 2004;33:433-441.

11. Cunningham SJ, Garratt AM, Hunt NP. Development of a conditionspecific quality of life measure for patients with dentofacial deformity: I. Reliability of the instrument. Community Dent Oral Epidemiol. 2000;28:195-201.

12. Apaydın A. İçinde: Harris M, Reynolds IR. Ortognatik Cerrahinin Temelleri, İstanbul: Nobel Tıp Kitabevi; 1992.

13. O’Brien K, Kay L, Fox D, Mandall N. Assessing oral health outcomes for orthodontics -measuring health status and quality of life. Community Dent Health. 1998;15:22-26.

Medical Science and Discovery, 2016; 3(4): 171-7 
14. Bennett ME, Phillips CL. Assessment of health-related quality of life for patients with severe skeletal disharmony: A review of the issues. Int J Adult Orthodon Orthognath Surg. 1998;14:65-75.

15. Siow KK, Ong ST, Lian CB, Ngeow WC. Satisfaction of orthognathic surgical patients in a Malaysian population. J Oral Sci. 2002;44:165171.

16. Nicodemo D, Pereira MD, Ferreira LM. Self-esteem and depression in patients presenting angle class III malocclusion submitted for orthognathic surgery. Med Oral Patol Oral Cir Bucal. 2008;13:48-51.

17. Rustmeyer J, Eke Z, Bremerich A. Perception of improvement after orthognathic surgery: The important variables affecting patient satisfaction. Oral Maxillofac Surg. 2010;14:155-162.

18. Campbell RL, Shamaskin RG, Harkins SW. Assessment of recovery from injury to inferior alveolar and mental nerves. Oral Surg Oral Med Oral Pathol. 1987;64:519-526.

19. Colella G, Cannavale R, Vicidomini A, Lanza A. Neurosensory disturbance of the inferior alveolar nerve after bilateral sagittal split osteotomy: A systematic review. J Oral Maxillofac Surg. 2007;65:17071715 .

20. Kim YK, Kim SG, Kim JH. Altered sensation after orthognathic surgery. J Oral Maxillofac Surg. 2011;69:893-898.

21. Raveh J, Vuillemin T, Ládrach K, Sutter F. New techniques for reproduction of the condyle relation and reduction of complications after sagittal ramus split osteotomy of the mandible. J Oral Maxillofac Surg. 1988;46:751-757.

22. Westermark A, Bystedt $\mathrm{H}$, Von Konow L. Inferior alveolar nerve function after mandibular osteotomies. Br J Oral Maxillofac Surg. 1998;36:425-428.

23. Wijbenga JG, Verlinden CR, Jansma J, Becking AG, Stegenga B. Long-lasting neurosensory disturbance following advancement of the retrognathic mandible: Distraction osteogenesis versus bilateral sagittal split osteotomy. Int J Oral Maxillofac Surg. 2009;38:719-725.

24. August M, Marchena J, Donady J, Kaban L. Neurosensory deficit and functional impairment after sagittal ramus osteotomy: A long-term follow-up study. J Oral Maxillofac Surg. 1998;56:1231-1235.
25. Westermark A, Bystedt $\mathrm{H}$, von Konow L. Inferior alveolar nerve function after sagittal split osteotomy of the mandible: Correlation with degree of intraoperative nerve encounter and other variables in 496 operations. Br J Oral Maxillofac Surg. 1998;36:429-433.

26. Ylikontiola L, Kinnunen J, Laukkanen P, Oikarinen K. Prediction of recovery from neurosensory deficit after bilateral sagittal split osteotomy. Oral Surg Oral Med Oral Pathol Oral Radiol Endod. 2000;90:275-281.

27. Van de Perre JP, Stoelinga PJ, Blijdorp PA, Brouns JJ, Hoppenreijs TJ. Perioperative morbidity in maxillofacial orthopaedic surgery: A retrospective study. J Craniomaxillofac Surg. 1996;24:263-270.

28. Kramer FJ, Baethge C, Swennen G, Teltzrow T, Schulze A, Berten J, et al. Intra-and perioperative complications of the LeFort I osteotomy: A prospective evaluation of 1000 patients. J Craniofac Surg. 2004;15:971977.

29. Lanigan DT, Hey JH, West RA. Aseptic necrosis following maxillary osteotomies: Report of 36 cases. J Oral Maxillofac Surg. 1990;48:142156.

30. Dolce C, Van Sickels JE, Bays RA, Rugh JD. Skeletal stability after mandibular advancement with rigid versus wire fixation. J Oral Maxillofac Surg. 2000;58:1219-1227.

31. Costa F, Robiony M, Politi M. Stability of Le Fort I osteotomy in maxillary advancement: Review of the literature. Int J Adult Orthodon Orthognath Surg. 1998;14:207-213.

32. Proffit WR, Turvey TA, Phillips C. Orthognathic surgery: A hierarchy of stability. Int J Adult Orthodon Orthognath Surg. 1995;11:191-204.

33. Hoffman G, Brennan PA. The skeletal stability of one-piece Le Fort 1 osteotomy to advance the maxilla: Part 1 . Stability resulting from nonbone grafted rigid fixation. Br J Oral Maxillofac Surg. 2004;42:221225 .

34. Proffit WR, Phillips C, Turvey TA. Stability after surgical-orthodontic corrective of skeletal class III malocclusion. 3. Combined maxillary and mandibular procedures. Int J Adult Orthodon Orthognath Surg. $1991 ; 6: 211-225$.

35. Rosen HM. Definitive surgical correction of vertical maxillary deficiency. Plast Reconstr Surg. 1990;85:215-221.

Copyright $(\mathcal{C} 2016$ The Author(s); This is an open-access article distributed under the terms of the Creative Commons Attribution License (http://creativecommons. org/licenses/by/4.0), which permits unrestricted use, distribution, and reproduction in any medium, provided the original work is properly cited. All Rights reserved by international journal of Medical Science and Discovery. 